\title{
Da adolescência em perigo à adolescência perigosa
}

\author{
Maria Rita de Assis César
}

\begin{abstract}
RESUMO
Este artigo trata da relação intrínseca entre a definição de adolescência e a idéia de delinqüência juvenil pré-existente, tomada de empréstimo da filantropia e dos tratados jurídicos do século XIX, a partir da qual delineou-se a figura do adolescente "ideal". Resulta da análise de livros e textos da (psico)pedagogia - produzidos entre a primeira década do século XX até os anos setenta -, os quais, por meio de um discurso próprio, traçaram definições e problemáticas, caracterizando cientificamente o surgimento de uma nova subjetividade, a adolescência. Essa pesquisa demonstra ainda alguns deslocamentos posteriores da definição de adolescência - como o rebelde sem causa e o jovem revolucionário e que, ainda com a criação desses novos personagens, a imagem do adolescente transgressor permaneceu vigente no imaginário social, definindo e determinando os destinos deste sujeito.

Palavras-chave: adolescência, delinqüência, (psico)pedagogia.
\end{abstract}

\begin{abstract}
This paper deals with the intrinsic relationship between adoslence definition and juveline delinquence, based upon philanthropy, and Judicial Treaties from the XIX century, from where the "ideal" adolescent was borrowed . It results from an analysis of (Psycho) Pedagogy books and texts from the first decades of the XX century until the seventies which by using their jargons, designed definitions which led to problematic situations, and so scientifically identified a new ADOLESCENCE. This paper explains why there are late phases of adolescence - as the rebel without a cause and the revolutionary young man - and consequently new characters are created, and the image of the criminal juveline remained in the social imaginary, thus defining and procastinating his/her fate.

Key-words: adolescence, delinquence, (psycho)pedagogy.
\end{abstract}

\section{Introdução}

Este trabalho tem como objetivo investigar os discursos que constituíram a adolescência como objeto de investigação e intervenção, a partir de textos produzidos por psicólogos e pedagogos desde o início do século XX. Desde o princípio, observou-se uma estreita relação entre adolescência e delinqüência juvenil, conceito proveniente dos movimentos de filantropia e dos discursos jurídicos do século XIX. Na tentativa de definir uma nova subjetividade, a adolescência, o discurso competente foi buscar seus elementos em definições de juventude e adolescência provenientes de temporalidades distintas, alinhavando artificialmente uma suposta continuidade histórica, muito embora as principais fontes de referência tenham se mantido, ou seja, a biologia, o higienismo e o eugenismo do século XIX.

Na Europa do século XIX e no Brasil das primeiras décadas do século XX, a implantação das reformas higienistas nos centros urbanos foi responsável pelo aparecimento de personagens que se encontravam à margem da ordem burguesa. Entre essas figuras marginais estavam a família disfuncional, a jovem prostituta e o delinqüente juvenil. O alvo das práticas intervencionistas e disciplinadoras, provenientes dos movimentos filantrópicos e, posteriormente, das instituições públicas e privadas recém-criadas, era a família, em especial a família operária, com sua presença maciça nos centros urbanos. A família operária e a família pobre foram compreendidas não apenas em termos da ausência de recursos financeiros, mas também, e principalmente, como carentes de recursos morais e intelectuais para educar seus filhos, sendo, portanto, objeto de investigação e intervenção das ações sociais. Dentro dessa família os seus filhos representaram um alvo particularmente importante de investimento pois, segundo o discurso intervencionista, tais crianças e jovens encontravam-se em situação de desatenção e vulnerabilidade nas ruas das cidades.

Uma vez identificadas pelos reformadores, as famílias disfuncionais foram responsabilizadas pela produção e reprodução dos problemas ligados a uma infância e a uma juventude sem assistência. A 
organização social estaria na dependência de normas elaboradas pelos reformadores, implicando a retirada da criança e do jovem do círculo de privação/depravação gerado por uma família deficiente, aquela que simplesmente criava seus filhos, ao contrário de educá-los, permitindo e estimulando que esses jovens e crianças permanecessem nas ruas, em busca de sustento próprio e da própria família. A rua, que representava um espaço de sociabilidade para os jovens e crianças, foi considerada pelos reformadores como o espaço físico e social responsável pela construção de uma vida de vícios, de depravação e de vagabundagem. Como o afirmou Margareth Rago, "No discurso do poder médico, a rua era representada como 'a grande escola do mal', espaço público por excelência onde se gerariam os futuros delinqüentes e criminosos irrecuperáveis”.

No discurso dos reformistas brasileiros do início do século, já era marcante o surgimento de uma preocupação para com os jovens ociosos e pobres, agrupados na figura dos menores vagabundos. Para esse discurso, tais jovens já haviam deixado a infância e circulavam livremente fazendo algazarras pelas ruas, atrapalhando a ordem e o trânsito. Para esses menores vagabundos, a sociedade possuía um aparato correcional e, principalmente, de segregação, internando-os nos asilos de menores abandonados ou enviandoos à escola de aprendizes de marinheiro. Táticas como esta, utilizadas para disciplinar e segregar jovens e crianças perigosos ou em perigo, foram comumente observadas nas metrópoles que se reestruturavam por meio de uma engenharia de guerra visando o combate às assim chamadas patologias sociais. Em decorrência das políticas de reforma social surgiu todo um exército de profissionais acrescido de um aparato jurídico especialmente concebido para prevenir e combater a criminalidade infantil e juvenil:

\begin{abstract}
A partir do final do século XIX, surgiu uma nova série de profissões: os assistentes sociais, os educadores especializados, os orientadores. Todas elas se reúnem em torno de uma nova bandeira comum: o trabalho social. Essas profissões encontram-se, atualmente, em plena expansão. [...] Não se vinculam a uma única instituição, mas, ao contrário, enxertam-se como apêndice nos aparelhos pré-existentes: judiciário, assistencial, educativo. Disseminados numa multiplicidade de lugares de inserção, guardam sua unidade, não obstante, em função de seu domínio de intervenção, que assume os contornos das classes 'menos favorecidas'. No interior dessas camadas sociais eles visam um alvo privilegiado, a patologia da infância na sua dupla forma; a infância em perigo, aquela que não se beneficiou de todos os cuidados da criação e da educação almejadas, e a infância perigosa, a da delinqüência. Toda a novidade do trabalho social, toda a sua modernidade, consistira justamente nessa atenção mais concentrada com relação aos problemas da infância, num questionamento conseqüente das antigas atitudes de repressão ou de caridade, na promoção de uma solicitude educativa sem fronteiras, visando mais a compreensão do que a sanção judiciária, substituindo a boa consciência da caridade pela busca de técnicas eficazes".
\end{abstract}

Investidos de uma teorização médico-científica, os movimentos de reforma social transformaram a diferença cultural e socioeconômica em patologia, concluindo pela necessidade de separar jovens e crianças de suas famílias disfuncionais. Os males físicos e morais da sociedade residiriam nessas famílias, as quais colocavam crianças e jovens em situação de risco ao permitir a sua permanência nas ruas, aspecto que constituiria a causa maior das transgressões sociais. Assim, os especialistas caracterizaram a delinqüência juvenil como conseqüência da pobreza, da ruptura dos laços familiares e também de condições precárias de moradia e lazer, compreendidas como patologias sociais. Somente uma educação adequada, ou a segregação, poderiam restituir esses indivíduos a um futuro minimamente aceitável. Com efeito, as instituições totais, os reformatórios, internatos ou as escolas profissionalizantes foram preparados para receber, além dos jovens delinqüentes e daqueles abandonados pelas famílias, todo e qualquer jovem e criança que vivesse em um ambiente favorável ao desenvolvimento dos vícios e transgressões. No centro dessas preocupações com a juventude e a infância formou-se uma teoria a respeito da delinqüência juvenil que, delineada pelas práticas reguladoras da sociedade, produziu tanto a figura da criança e do jovem estigmatizados, como também o seu contra-modelo idealizado. Simultaneamente às primeiras teorizações sobre a adolescência, as instituições responsáveis pelos cuidados e educação dos jovens definiram um tratamento discursivo que configurava e produzia a figura do delinqüente juvenil.

A caracterização das transgressões que delineou a imagem da delinqüência juvenil foi circunscrita por meio de um recorte de gênero e da sexualidade. A transgressão dos rapazes foi descrita através da desordem social, isto é, os pequenos furtos, a bebida, o cigarro, a ociosidade e a prática do onanismo, enquanto para as garotas a transgressão foi demarcada pelo exercício ilícito da sexualidade. Além do exercício consentido da sexualidade, também as situações de abuso sexual, tanto em casa como nas ruas, foram consideradas como uma forma de condução à delinqüência, colocando a garota em situação de transgressão: a iniciação sexual 
fora do casamento foi vista como a porta de entrada da repetição do vício. Em relação aos garotos, o exercício da sexualidade não representou um problema de acentuada gravidade, excetuando-se a masturbação e os comportamentos e as práticas homossexuais, classificados como vícios próprios da delinqüência juvenil masculina.

Para os jovens e crianças das famílias desprovidas de recursos financeiros, a rua representava um espaço de convívio público e de lazer sem as normas das instituições, além de ser o local de aprendizado das regras de sobrevivência. A rua constituía um campo de possibilidade de pequenos trabalhos para vendedores de jornal, entregadores de folhetos, carregadores de pacotes, floristas e plumistas entre outras atividades. Entretanto, aos olhos dos reformadores e novos especialistas da adolescência, a rua era o local por excelência do aprendizado dos vícios e da delinqüência, do lazer sem regras e do ócio, em suma, da delinqüência juvenil, cuja versão feminina centrava-se especialmente na prostituição. Foi a partir desta concepção negativa do espaço da rua que se iniciou um trabalho de organização do lazer como prevenção das formas viciosas de convívio social, decorrendo daí uma valorização dos esportes e das práticas esportivas em equipe para os jovens. Aos olhos dos reformistas, a rua tingia-se de cores sombrias e assustadoras, sendo considerada como o lugar da precocidade juvenil, interpretada como uma patologia associada à pobreza e à falta de controle por parte dos pais, que permitiam a jovens e crianças iniciar-se precocemente em atividades designadas aos adultos, tais como a vida em grupo ou em gangs, os pequenos trabalhos, as práticas sexuais e as lutas corporais pela manutenção de um território de ação e circulação na cidade. No discurso dos reformistas a precocidade foi considerada uma característica degenerada e anômala, temida pela sociedade e associada, segundo o jargão da inferioridade racial, aos povos mediterrâneos e tropicais e às imagens da pobreza e da falta de civilidade.

Ao longo do século XIX foi se constituindo um aparelho judicial especialmente concebido para o cuidado da infância e da juventude, tendo em vista tratar da delinqüência juvenil. Esses novos personagens já apareceram orientados pela psicologia da adolescência e não mais pelas regras moralizadoras dos filantropos do século XIX. Na medida em que aumentaram as demandas para as medidas preventivas, aumentaram também as taxas de delinqüência juvenil. Nos Estados Unidos, por volta de 1910, as acusações se voltavam para furtos de frutas, de brinquedos, cigarros ou, ainda, por brincar nas ruas e provocar arruaças. Entre os jovens, as acusações mais comuns eram as ofensas a policiais, a prostituição e os crimes contra a propriedade, classificados como condutas anti-sociais. Nos anos vinte, observou-se que $60 \%$ dos delitos cometidos por rapazes eram atentados contra a propriedade, enquanto que em relação às as moças entre 60 a $80 \%$ dos casos de delinqüência eram relativos à imoralidade.

Com a consolidação do discurso da psicologia da adolescência no início do século XX, a precocidade deixaria de ser uma preocupação relativa ao desenvolvimento normal da infância e da adolescência, isto é, deixaria de ser um problema. A partir de então, a transgressão seria concebida como uma característica própria dessa fase da vida, ao passo em que os transgressores adultos seriam agora considerados como indivíduos imaturos ou adolescentes tardios. Nos textos de psicologia e educação o risco da delinqüência juvenil configurava uma possibilidade incorporada de maneira constitutiva à própria definição do conceito de adolescência. A novidade introduzida pelo discurso da psicologia do desenvolvimento em relação ao antigo discurso filantrópico, que enxergava a delinqüência juvenil como vinculada apenas às patologias sociais, foi o estabelecimento de uma ligação natural entre delinqüência e adolescência. A partir de então, a delinqüência juvenil passou a ser abordada não apenas através do ponto de vista das teorias sociais e morais, mas também e cada vez mais pela perspectiva naturalizante da psicologia do desenvolvimento, que colocava o comportamento transgressor da adolescência no âmbito da natureza.

Tal como estabelecida no discurso científico a partir das primeiras décadas do século $\mathrm{XX}$, a adolescência apresentou-se como uma fase do desenvolvimento humano na qual o risco da transgressão e, conseqüentemente, da delinqüência, tornaram-se um dado da natureza, rondando de forma espectral aqueles sujeitos. Assim, a díade adolescência/delinqüência constituiu uma máscara de dupla face que, adaptada ao rosto do jovem, criou um indivíduo caracterizado por duas possibilidades interdependentes, porém incompatíveis entre si, o adolescente domesticado, o modelo ideal de juventude inocente, e o adolescente delinqüente, a sua necessária contrapartida fundamental. A partir dessa teorização da psicologia do desenvolvimento sobre delinqüência juvenil todos os adolescentes encontravam-se em situação de risco, estando potencialmente sujeitos às intervenções sociais. Entretanto, tais intervenções se dariam de maneira diferenciada, de acordo com as condições socioeconômicas dos adolescentes, distribuindo-se entre as escolas secundárias, os clubes sociais, as associações esportivas, as escolas técnicas e vocacionais, os asilos para jovens abandonados e os reformatórios para jovens delinqüentes. A teoria da adolescência normal continha em seus fundamentos a idéia da patologia e da delinqüência, aprisionando o conceito de adolescência em um 
paradoxo insolúvel. O sujeito adolescente que se consolidou no discurso (psico)pedagógico foi fruto dessa cristalização paradoxal, que também determinou a tarefa educativa como um espaço de constante tensão, trazendo consigo o risco iminente da falha. A vigilância foi a principal arma de combate ao problema da delinqüência, e a segregação foi tomada como uma solução para o problema já instalado. Da rebeldia natural da adolescência à delinqüência juvenil a distância percorrida foi curta e os passos dados seguiram a mesma lógica evolucionista que estabelecera a adolescência como uma das fases da evolução humana. A adolescência das tempestades e tormentas, das crises, dos problemas, da agressividade e da rebeldia caracterizaria, cinqüenta anos depois, o rebelde sem causa e a juventude transviada, imagens da juventude consagradas pelos veículos de comunicação de massa, deixando marcas duradouras no imaginário ocidental.

$\mathrm{O}$ recorte de gênero foi determinante nas caracterizações da adolescência delinqüente. Para o psicólogo inglês W. Wall, os garotos seriam naturalmente dotados de comportamento difícil e, por isso, mais propensos à delinqüência, muito embora esse comportamento agressivo fosse esperado pela própria sociedade. Segundo o mesmo autor, as garotas seriam mais sonhadoras e instáveis, correndo menos riscos; porém, quando afetadas pela delinqüência, esta se caracterizaria pela lascívia. Ainda para esse autor, o tempo da conduta ruim ou a idade da delinqüência demarcar-se-iam entre os doze e os catorze anos, e o cinema, um fenômeno de massa amplamente freqüentado pela adolescência, foi considerado uma influência poderosa no caminho para a delinqüência, não tanto pelas imagens mostradas, mas pelo vício em que se poderia transformar, podendo levar os adolescentes a roubar para assistir às sessões.

No início dos anos cinqüenta, o psicólogo norte-americano Frederic Werthan publicou o livro Seduction of the Innocence, no qual apontava o caráter nefasto da cultura de massas na determinação do fenômeno da delinqüência juvenil, criticando o descaso do governo americano para com as evidências dessas influências negativas. Para Werthan, os comics (histórias em quadrinhos) teriam uma forte influência sobre o comportamento criminoso, pois, segundo ele, praticamente todos os adolescentes que, acusados de crimes, passavam por tratamento no hospital psiquiátrico onde clinicava, possuíam em seu histórico o intenso consumo deste tipo de literatura, com suas histórias recheadas de sexo e horror. Werthan pretendeu mostrar em seu livro a similaridade entre os crimes cometidos pelos adolescentes e aqueles descritos nas revistas em quadrinhos, visto que, para ele, os adolescentes delinqüentes transportariam a situação da narração fictícia para a esfera do real. Ainda assim, Werthan também não deixava de apontar a família e a escola como instâncias responsáveis pela falta de cuidados em relação ao adolescente, acrescentando ainda que os delinqüentes estariam desprotegidos do ponto de vista social e psicológico. Foi assim que a delinqüência começou a ser transformada em um fenômeno de massa, o qual não mais poderia ser compreendido apenas pela psicologia individual. $\mathrm{O}$ autor também não descartou a hipótese da presença dos impulsos instintivos favorecedores da delinqüência, mesmo se, para ele, as influências do ambiente e, em especial, da cultura de massas, fossem fundamentais para a manifestação da delinqüência. Deste modo, a delinqüência juvenil não poderia ser reduzida apenas às suas causas biologicamente determinadas já que seria um fenômeno socialmente e continuamente recriado pelos adultos, refletindo os valores da própria sociedade. Para Werthan, a escola tornava-se um local perigoso pois representava um ponto de encontro entre os adolescentes no qual eles poderiam se organizar em grupos para cometer delitos sob a influência das revistas em quadrinhos, constituindo-se, ainda, em um local preferencial para a disseminação das drogas.

Os textos brasileiros da década de sessenta sobre a adolescência enfatizaram o controle familiar como uma influência importante para o seu desenvolvimento saudável, proclamando a noção de medida na educação dos filhos como um fator fundamental para a prevenção da delinqüência juvenil, classificada segundo padrões de classe social. Segundo estes textos, os adolescentes provenientes das famílias ricas seriam o resultado do desejo paterno de saciar todas as vontades dos filhos, o que lhes abriria as portas para os prazeres e vícios, as aventuras, o sexo, o álcool e os entorpecentes. Segundo o psicólogo e pedagogo Imídeo Nérici,

Os chamados playboys, lambretistas, os constituintes da tão propagada juventude transviada, por exemplo, são provenientes, em geral, dessa classe social. Esses pobres rapazes revelam, via de regra, deficiente assistência afetiva, ou excessiva assistência dessa natureza, suplementada com a econômica. Estes adolescentes são, na verdade, autênticos desamparados da família, que os cumula de facilidades, os abandona à sua própria sorte, no meio das mesmas. Rapazes criados na mais absoluta irresponsabilidade e têm os seus mínimos desejos satisfeitos, porque são criados como autênticos donos do mundo. [...] O que impressiona é que muitas autoridades passam a agir coniventemente com este tipo de comportamento social, e que os pais não sejam responsabilizados judicialmente pelas estrepolias dos filhos. Essa falta de repressão é que dá ao adolescente a convicção de um conluio generalizado, com bases em poderes sociais inesgotáveis, de que se julga possuidor. 
Ainda para os (psico)pedagogos brasileiros da década de sessenta, a rua continuava a ser uma grande fonte de preocupação, e eles defenderam, como os seus colegas estrangeiros do início do século, a organização do lazer. Para Ferraz, por exemplo, a prática de delitos poderia decorrer das atividades esportivas praticadas nos terrenos baldios e nas ruas, isto é, na ausência de locais apropriados e vigiados. Para ele, o desejo natural de agrupar-se poderia se resolver com a criação de clubes agrícolas, com o escotismo e as sociedades atléticas, sendo fundamental evitar o ócio e as companhias desaconselháveis. Ferraz corroborou a teoria da natureza instintiva da delinqüência, conjugando-a a fatores sociais tais como a família e os problemas socioeconômicos. Ele explicou o uso de substâncias alucinógenas e entorpecentes referindo-o às características inatas da adolescência, caracterizada pela "busca insaciável do gozo". O álcool, o éter e os "estupefacientes" em geral colaborariam para a dissolução dos conflitos mentais e da angústia, motivo em função do qual os adolescentes se viciariam facilmente na bebida e na maconha, entre outras substâncias. Outros autores teorizaram a adolescência como uma condição marginal, tanto por ser provisória quanto por instigar a prática de delitos criminosos. Desse modo, a adolescência foi caracterizada como um período de busca da identidade, o que se deixaria perceber no emprego de uma simbologia de grupo interpretada pelos especialistas como uma forma de "semi-identidade" expressa nas roupas, na linguagem diferenciada e em atitudes próprias, muitas vezes identificadas com grupos criminosos. Estreitando ainda mais as relações entre adolescência e delinqüência, outros autores ainda argumentaram que a maioria dos adolescentes do sexo masculino e um grande número de adolescentes do sexo feminino teriam necessariamente praticado atos de delinqüência. A partir do momento em que se alargou o conceito das atitudes que constituíam atos de delinqüência, seria apenas natural que os (psico)pedagogos se alarmassem com o aumento das suas incidências. Os delinqüentes juvenis foram caracterizados como seres de inteligência inferior comprovada por testes, muito embora também se afirmasse existir delinqüentes muito inteligentes. Segundo a psicóloga Odette Cardoso, "médicos, psicólogos e orientadores educacionais" poderiam "agir com mais segurança e aconselhar melhor os pais" se estivessem de posse do eletroencefalograma do adolescente sob suspeita de cometer atos delinqüentes, aquele no qual o "sistema nervoso não está acompanhando o desenvolvimento do corpo". Para Cardoso, sem a família, a proteção natural da adolescência, criar-se-iam "pequenos monstros", "fumadores de maconha, ladrões de carro e homossexuais".

As imagens que se cristalizaram no imaginário social enquanto representações privilegiadas da adolescência transgressora não foram aquelas da delinqüência juvenil associadas aos jovens pobres, sujos e brutos, apresentados frente às cortes judiciais e vindos de famílias desordeiras e descuidadas. A imagem típica da adolescência foi um produto dos anos cinqüenta, particularmente da próspera sociedade norte-americana do pós-guerra, que consagrou a figura da adolescência transgressora no cinema e na mídia em geral como o "rebelde sem causa", o "jovem transviado". Com o término da guerra, deslocou-se a tônica do jovem ou do adulto combatentes para a figura do teenager, termo que começou a apresentar um uso corrente a partir de 1945. Com efeito, o conceito de adolescência atingiu a sua maturidade durante a década de 50, sendo significativo que obras que se tornaram verdadeiros símbolos da adolescência, como On the Road, escrito em 1941 por Jack Kerouac, e Rebel without a cause, escrito em 1944 por Robert Lindner, somente tenham se tornado populares a partir da segunda metade da década de 50. A obra de Lindner tornar-se-ia internacionalmente famosa a partir da sua versão cinematográfica dirigida por Nicholas Ray, em 1955, tendo James Dean e Nathalie Wood como os protagonistas principais. Este filme muito contribuiu para a formação da imagem típica da "adolescência", associada aos carrões 'envenenados', às lambretas, aos blusões de couro e aos novos cortes de cabelo. Como bem o observou Passerini, “(...) a mentalidade que criou o delinqüente como tipo se parece com aquela que criou o tipo adolescente: primeiro, certos traços físicos e/ou mentais são definidos como próprios do tipo e em seguida a definição é usada para explicar o comportamento dos jovens".

A indústria musical da década de cinqüenta também passou por uma revolução de ritmos e de performers com o nascimento do rock and roll, verdadeira tempestade rítmica que rapidamente se transformou em fenômeno de mídia e de massa, tendo como alvo prioritário os adolescentes. Nesse contexto, uma das figuras mais agressivas e desconcertantes face aos costumes consolidados da classe-média norteamericana foi Elvis Presley, um cantor branco que cantava com voz e sotaque de negro sulista cantor de blues. Rebolando e utilizando uma gestualização repleta de alusões sexuais, Elvis também escandalizava por ter aparecido em uma época e uma região extremamente marcados pela segregação racial. Ao mesmo tempo em que causava desconforto para os padrões da normalidade da white middle-class suburbana, generalizada na cultura norte-americana devido à prosperidade econômica do pós-guerra, ele se tornava um fenômeno de massa dentro e fora dos Estados Unidos. A preocupação com a influência de tais figuras midiáticas foi expressa nos documentos do "Subcomitê do Senado sobre a Delinqüência Juvenil", em que se chegou a afirmar que "o gângster de amanhã é o tipo Elvis Presley de hoje". 
No Brasil dos finais dos anos sessenta e início dos anos setenta tornou-se comum que os especialistas associassem as tradicionais descrições da adolescência à idéia de subversão política. Não por acaso, o discurso (psico)pedagógico passou a alertar as famílias para um novo perigo: o potencial destrutivo e transgressor da adolescência poderia ser canalizado e posto a serviço não apenas de grupos criminosos, mas também de movimentos ideológicos rebeldes e hostis à ordem social do país. Sintomaticamente, durante esse período a figura do jovem transgressor brasileiro esteve bastante associada à resistência política e à guerrilha contra o regime militar, caracterizando um deslocamento na imagem padrão da adolescência cujo precedente foram as manifestações políticas estudantis ocorridas nos Estados Unidos e na França a partir da segunda metade dos anos sessenta. Neste momento, a imagem negativa da adolescência seria temporariamente dissociada da figura do adolescente conformista ou do rebelde sem causa. No correr dos anos sessenta, o debate sobre a adolescência envolvendo psicólogos, pedagogos, sociólogos e representantes das instituições educacional e judicial foi se transformando, e termos como delinqüente juvenil foram sendo substituídos por alusões à "cultura de jovens".

Os deslocamentos na esfera do discurso dos especialistas sobre a adolescência já podiam ser observados desde o final dos anos cinqüenta, quando o psicólogo Edgar Friedenberg surgiu como uma voz dissonante, propondo uma tese sobre o fim da adolescência em sua obra de 1959, The vanishing adolescence. Além da sua tese sobre o desaparecimento da adolescência tal como construída segundo os ideais de dependência e conformismo, dado que esta faixa etária ocupava cada vez mais espaço nos diferentes nichos da vida pública, Friedenberg também apontou para uma possível caracterização do adolescente em termos das subculturas de minorias, em oposição aos antigos modelos ideais da adolescência. Para este autor, a crise adolescente não se relacionava à natureza daqueles indivíduos, como os psicólogos anteriores haviam pensado, mas seria uma crise decorrente da posição minoritária que a adolescência ocupava na sociedade, em razão de sua idade. Um pouco antes de Friedenberg, o estudo do sociólogo James Coleman, de 1955, também já trabalhava com a idéia de "subcultura adolescente", atribuindo um caráter de alteridade para a adolescência, isto é, caracterizando-a em termos de uma cultura que partilharia de vários dos elementos das culturas dominantes, mas que, no entanto, se distinguiria por uma simbologia própria, ou ainda por seu caráter desviante. $\mathrm{O}$ conceito de subcultura adolescente foi proposto como representativo de uma faixa etária diferenciada, referindo-se ao conflito de gerações e demarcando-se por roupas, música, adereços e preocupações sociais e sexuais que ficariam cada vez mais evidentes a partir dos anos cinqüenta, graças a uma cultura de massas que reproduzia os ícones da juventude.

Para Friedenberg, os anos cinqüenta representaram o apogeu da idéia de adolescência bem como mostraram os limites dessa mesma idéia, anunciando o seu fim, isto é, o final da caracterização de adolescência tal como ela fora construída pelos manuais de psicologia do desenvolvimento desde o início do século. Segundo os argumentos de Friedenberg, a adolescência representaria uma faixa da população que começava a forçar efetivamente os contornos da sua própria caracterização, ampliando os limites das práticas sexuais anteriormente consideradas ilícitas, diversificando os seus nichos de consumo e alargando os seus espaços de intervenção na vida pública. Desta maneira, os adolescentes inverteriam e até mesmo destruiriam os muros que, ao delimitarem sua própria definição, aprisionavam seu campo de ação. Outros autores com teses semelhantes às de Friedenberg também apontaram para uma dissolução da imagem do ideal de vida adulta, da solidez dos laços do trabalho e da vida em família, que cada vez mais mostravam ser uma ficção irrealizável, frustando aqueles indivíduos que haviam acreditado na falácia da estabilidade das instituições e nas promessas de felicidade incorporadas pelos modelos institucionais:

[...] a adolescência tornava-se obsoleta, pois a integração pessoal não podia mais ser o velho ideal de maturidade, então irrealizável. Os próprios adultos transmitiam aos adolescentes sua ansiedade e falta de clareza quanto aos papéis sociais. A bola era assim devolvida aos pais e professores, definidos como indivíduos insuficientemente caracterizados, transformados em seres anônimos por processos que reduziram todos à multidão ou à massa.

Nesses termos, foram os próprios criadores da adolescência, isto é, o discurso hegemônico da psicologia do desenvolvimento e as instituições que sustentaram esse discurso, os responsáveis pela demarcação de uma fragilidade intrínseca do conceito de adolescência. A constatação da fragilidade das instituições, sobretudo da escola e da família, acrescida do dado da participação dos adolescentes em papéis anteriormente limitados ao universo adulto, acabou por determinar um embaralhamento das fronteiras que antes separavam adultos e adolescentes. A partir do início dos anos setenta, um dos resultados dessa modificação pôde ser detectado na aproximação entre adultos e adolescentes, de sorte que mesmo o 
comportamento denominado maduro dos adultos passaria a ser contaminado pelos mesmos traços de instabilidade que antes definiam exclusivamente a adolescência. Assim, foi também a própria idéia de adolescência que acabou por revelar o fim da idéia de família ideal, demonstrando que o modelo de maturidade proposto pelas regras sociais vigentes contribuía para a própria frustração e angústia dos adultos, demonstrando assim a obsolescência de um projeto para o qual os adolescentes vinham sendo preparados já desde o começo do século.

\section{REFERENCIAS}

ARAÚJO, R. M. B. A vocação do prazer. A cidade e a família no Rio de Janeiro republicano. Rio de Janeiro: Rocco,1993. p.160.

BROOKS, D. F. La psicología de la Adolescencia. Buenos Aires: Kapelusz, S.R.L, 1948. p. 406.

CARDOSO, O. B. O livro do adolescente. Rio de Janeiro: Conquista,1968.

COLEMAN J. S. The adolescent society. The social life of the teenager and its impact on education. Glecoe: Free Press, 1961.

DONZELOT, J. A polícia das famílias. 2. ed. Rio de Janeiro: Graal, 1986. p.75.

FERRAZ, J. S. Psicologia do Adolescente.

FRIEDENBERG, E. Z. The image of the Adolescence Minority. In: ROGERS, D. (Org.) Issues in Adolescent Psychology. 2. ed. New York: Appleton-Century-Crofts, 1972.

GILLIS, J. R. Youth and history. Tradition and change in european age relation, 1770-present. New York: Academic Press, 1981.p. 173.

GOTTILEB, D.; REEVES, J. A questão das subculturas juvenis. In: BRITTO, S. (Org.) Sociologia da juventude: para uma sociologia diferencial. p. 70-71. 1968.

HEINE, W. S. The development of leisure and the transformation of working-class adolescence, Paris, 1830-1940. Journal of Family History.

JERSILD, A. T. Psicologia da adolescência. 3. ed. São Paulo: Nacional, 1967. p.404.

MANHOOD, L.; LITTLEWOOD, B. The vicious girl and the street-corner boy: sexuality and gendered delinquent in scottish child-saving movements, 1850-1940. Journal of the History of Sexuality, Chicago, v.4, n.4, p. 550, apr. 1994.

MUUSS, R. E. Theories of adolescence. p. 94.

NÉRICI, I. G. Adolescência - O drama de uma idade. 3. ed. Rio de Janeiro: Fundo de Cultura, 1967. p.153.

PASSERINI, L. A juventude, metáfora da mudança social. Dois debates sobre os jovens: a Itália fascista e os Estados Unidos da década de 1950. In: LEVI, G.; SCHIMITT, J. História dos jovens. São Paulo: Companhia das Letras, 1994. v. 2, p.362.

PFROMM NETTO, S. Psicologia da adolescência. 5. ed. São Paulo: Pioneira/MEC, 1976.

RAGO, M. Do cabaré ao lar: a utopia da cidade disciplinar. Brasil 1890-1930. 3. ed. São Paulo: Paz e Terra, 1997. p. 121.

SCHMITT, J. História dos jovens. São Paulo: Companhia das Letras, 1994. v. 2, p. 361.

SIMMONS, J. Censoring rebel. Journal of Popular Film and Television, v. 23, n.2, p. 57, 1985.

WALL, W. D. The adolescent child. London: Methuen \& Co.,1948.

WERTHAN, F. Seduction of the innocence. New York: Kennikat Press, 1953. 